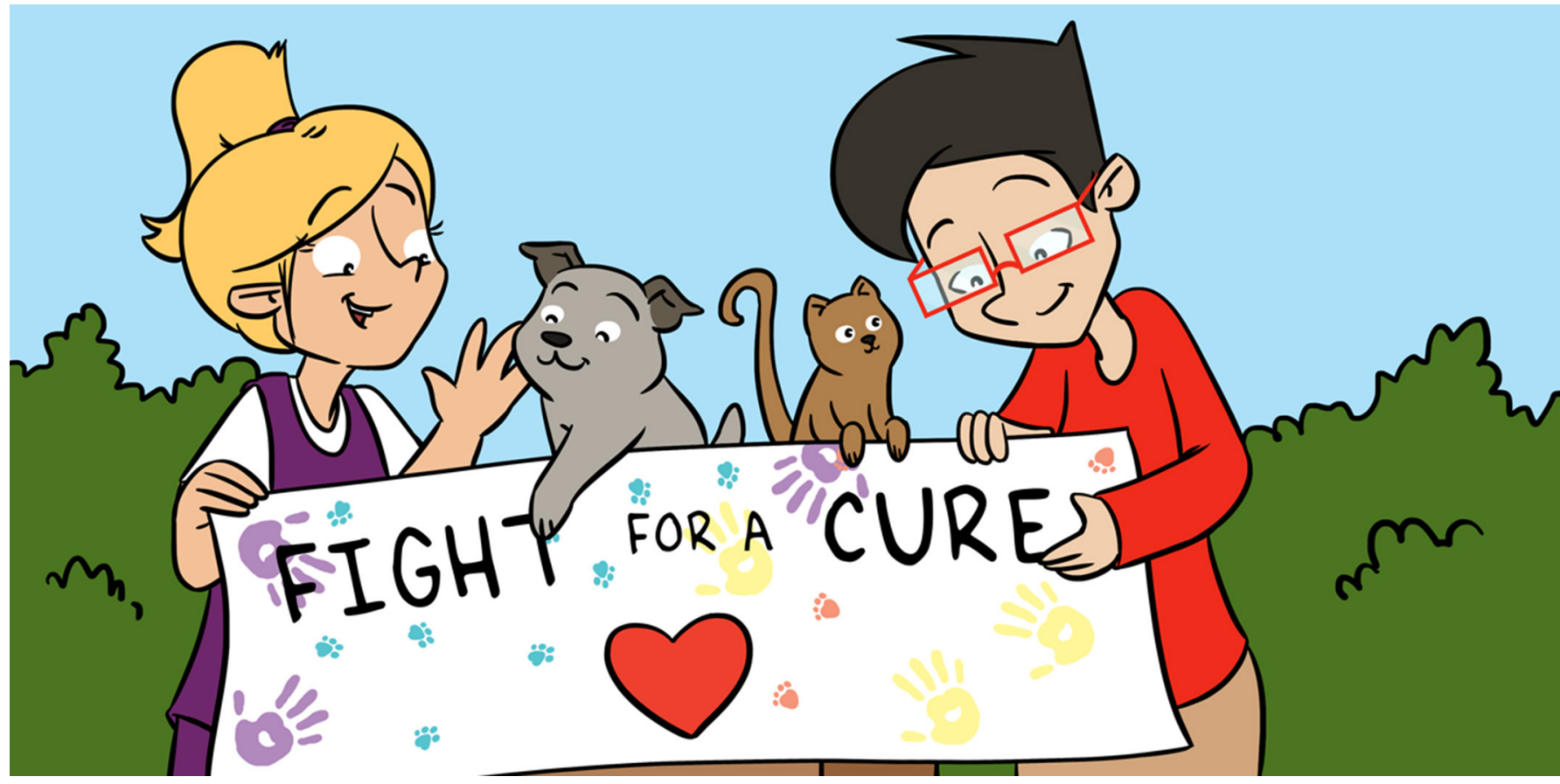

\title{
HOW CAN DOGS AND CATS HELP TO CURE HUMAN CANCERS?
}

\section{Laura Bongiovanni ${ }^{1 *}$, Philip J. Bergman ${ }^{2}$ and Alain de Bruin ${ }^{3}$}

${ }^{1}$ Faculty of Veterinary Medicine, University of Teramo, Teramo, Italy

${ }^{2}$ Katonah Bedford Veterinary Center, Bedford Hills, NY, United States

${ }^{3}$ Department Biomolecular Health Sciences, Faculty of Veterinary Medicine, Utrecht University, Utrecht, Netherlands

YOUNG REVIEWER:

ISABELLE

AGE: 11
Like their owners, dogs and cats can be affected by several types of cancer, and some types are very similar to those seen in people. Unfortunately, there is still no cure for several types of cancer. How can humans' best friends help? If a new therapy to fight cancer works well in pets, it is likely to also be effective in people with the same type of cancer. Scientists, medical doctors, and animal doctors are working together to develop new therapies that destroy cancer cells and save patients. Since the characteristics of certain types of cancer are very similar between humans and pets, new medicines that work in pet dogs or cats may also benefit human patients. Studying these "human-like" cancers in pets may speed up the development of effective anti-cancer drugs and will help to cure not only more dogs and cats, but also people with cancer. 


\section{ANIMALS CAN GET CANCER TOO!}

Just like humans, pets may become sick, develop severe diseases, and die from them. One of these diseases is cancer. Pets such as dogs, cats, horses, ferrets, and rabbits can spontaneously develop cancers. Dogs and cats are our most common pets and are often considered to be part of the family. Many owners will do anything to save their beloved friend, so dogs and cats often undergo surgery and medical treatments. Because of this, cancers of dogs are the most studied animal cancers, and there is a lot of information about them. Veterinarians (animal doctors) and veterinary scientists spend a lot of time studying pet cancers, both to cure pets and to understand pet cancers: the genes involved, how severe each type is, and how cancers develop and progress over time. Thanks to all the studies already conducted on dog cancer patients, we now know that several cancer types in dogs are very similar to those of people, including cancers of the bone, mouth, lymph nodes, and brain. Furthermore, the bodily systems of dogs, including the immune system, share many similarities with the systems of the human body [1]. So, what if dogs, cats, and humans could benefit from the same cancer research?

\section{THE LIVES OF DOGS AND CATS}

Dogs and cats live closely with their owners for their entire lives. People spend time at home with their pets, play together in the garden, take long walks outside, and go on vacations with them. Some dogs even go to work or shopping with their owners. Therefore, these animals are exposed to the same environmental risk factors that humans are, some of which can cause cancers. For example, studies on air pollution exposure demonstrated that humans and their pets are exposed to the same dangerous pollutants. As a result, dogs and cats can get sick from these environmental factors, just like their owners can.

It is important to remember that dogs are the oldest domesticated species and have lived with people for thousands of years. Over those years of living with us, dogs have adapted to humans, helping people in their work and daily activities, and becoming "man's best friend." This did have an effect also on dogs' genes and body structures, which resulted in the many different dog breeds that we know today. Then, 15 years ago, the entire canine genome was sequenced, revealing an amazing discovery: the dog and human genomes are very similar [2]! This means that studying the genes of specific breed of dogs that develop "human-like" cancers can help us to understand the role of those genes in human cancers, too.

Of the dog.

Also, the lifespans of dogs and cats are much shorter than the lifespan of humans. Dogs and cats live about 12-14 years. This means the "speed" of a pet's life is about six to seven times faster than a human life. This is important because, if you want to evaluate whether a new 
Figure 1

Stages of anti-cancer drug development.

\section{COMPARATIVE}

\section{ONCOLOGY}

Discipline that integrates the naturally occurring cancers seen in veterinary patients into more general studies of cancer biology and therapy.

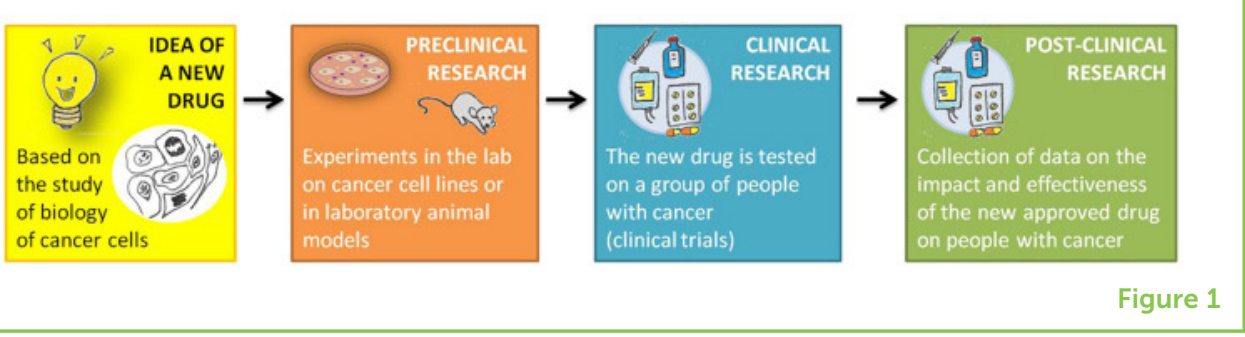

therapy approach works in dogs or cats, you do not have to wait as long to see the effect as you would with humans. What if dogs and cats that develop cancer could help doctors to develop new cancer-fighting treatments?

\section{HOW ARE ANTI-CANCER DRUGS DEVELOPED?}

Currently, there are only a few drugs that can cure cancer patients and these drugs often cause severe side effects. Doctors and scientists are committed to finding better ways to cure cancer. The process starts with an idea for a potential new drug. Cancer researchers come up with these ideas by carefully studying different types of cancers, cancer cells which they are composed and their important features. Getting from the idea of a new drug to a treatment for patients is a very long process. First, researchers start with laboratory experiments. Only after they have collected a lot of laboratory data can they start to test the new drug on small groups of people with cancer. At this stage, doctors and scientists make sure the drug is effective at treating cancer and safe for patients. Research universities, government agencies, and drug companies work together in this process, until the new drug is approved by official national agencies. The development of a new anti-cancer drug and its approval for use in patients takes $\sim 10$ years, and costs up to $\$ 2,000,000,000$ USD (Figure 1). Unfortunately, $<1$ in 20 attempts at drug development actually results in an approved drug, so this process is very inefficient. The poor success also explains why many anti-cancer drugs are so expensive: because drug companies need to compensate for the money they invested into drugs that did not pass testing to become medicines [1].

\section{HOW DOGS AND CATS CAN HELP PEOPLE WITH CANCER}

Studies of animal patients that naturally develop cancers can help researchers find new ways to cure both animal and human cancer patients. All the data and new information obtained from studying dogs and cats with cancer can be combined with more general studies on cancer biology and therapy (Figure 2). There is now a discipline called comparative oncology, in which human and veterinary scientists work together, "comparing" how cancers develop, progress, and can be 
Figure 2

Dogs and cats can help with the development of new anti-cancer drugs.

\section{MELANOMA}

Cancer arising from pigmented cells called melanocytes, present in the skin and mucosa.

\section{OSTEOSARCOMA}

Cancer arising from cells of the bone.

\section{GLIOMA}

Cancer arising from specialized cells of the brain, called glial cells.

\section{LYMPHOMA}

Cancer arising from cells of the immune system called lymphocytes, which are abundant in lymph nodes.

\section{SQUAMOUS CELL} CARCINOMA

Cancer originating from the cells of the internal surface (mucosa) or external surface (skin) of the body.

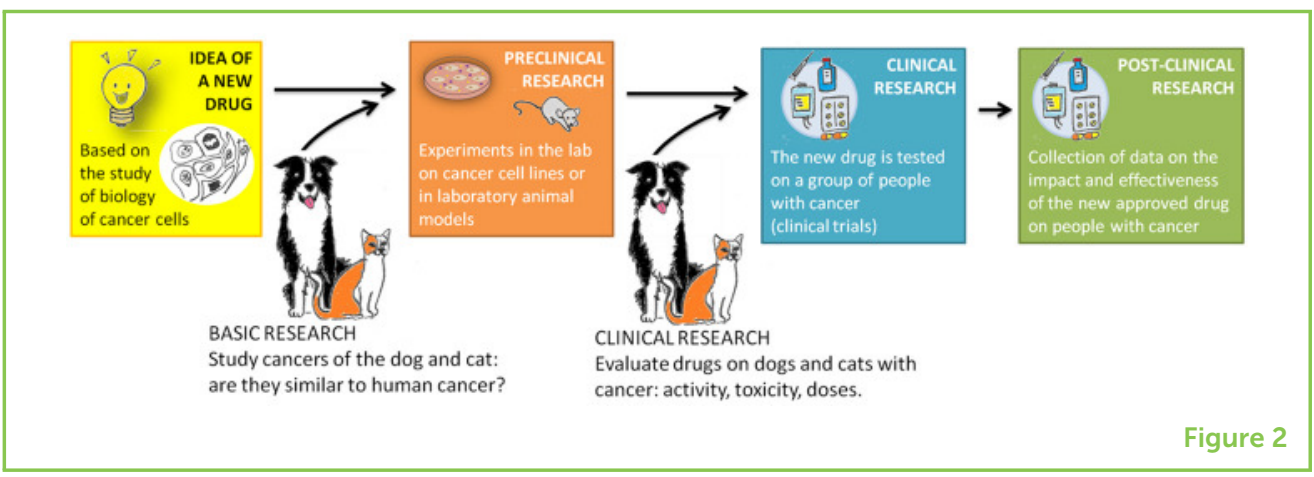

treated in different species. This helps researchers find the best way to beat this serious disease, in both people and animals [3].

Thanks to the daily work of veterinary scientists committed to studying cancers in their animal patients, there are now several types of dog and cat cancers that are believed to be good models for human cancers. Examples of "human-like" cancers in dogs include cancers of the mouth (melanoma), bone (osteosarcoma), brain (glioma), and lymph nodes (lymphoma). Examples in cats include cancers of the mammary glands or mouth (squamous cell carcinoma). Melanoma of the mouth is frequently observed in dogs, but is very rare and extremely malignant in people, rendering this model even more precious. Gliomas, lymphomas, and osteosarcomas are reported in dogs just like in kids and young adults, making dogs an invaluable resource for studying these serious diseases [4]. Feline oral squamous cell carcinoma is a frequently reported tumor with an aggressive behavior that is very similar to the head and neck cancer frequently detected in humans [5].

Interestingly, cancers are not the only diseases that are similar between pets and humans! There are several other diseases of pets that might help us to learn about human diseases and treat human patients (Figure 3).

When dogs or cats are treated with new anti-cancer drugs, veterinarians collect lots of important information about whether the drugs kill the cancer cells and if the animal patients can be cured (drug activity). Information is also collected about whether drugs cause side effects (drug toxicity), as well as how much of a drug should be taken (dose) and how frequently (schedule). All these data generated from the treatment of cat and dog patients can be used to develop a parallel treatment strategy for human cancer patients. This has already been done for some types of cancer and more studies are ongoing. It seems that studying dogs and cats that develop cancers can help researchers improve the speed at which anti-cancer drugs are created, reduce the costs, and increase the percentage of drugs that become approved. 
Figure 3

Did you know that there are a lot of other diseases that animals develop, besides cancer, and that these can help researchers study human diseases? In this table, you can see some examples of diseases for which pets are helpful for improving the knowledge of, and therapy for, human diseases. In addition to dogs and cats, horses can also spontaneously develop specific diseases that are very similar to the human ones.

\begin{tabular}{|c|c|c|}
\hline DISEASES OF & PETS & DISEASE \\
\hline Cardiovascular system & Cat, dog & $\begin{array}{l}\text { Feline Hypertrophic } \\
\text { Cardiomyopathy }\end{array}$ \\
\hline Immune system & Cat, dog, horse & $\begin{array}{l}\text { X-Linked Severe Combined } \\
\text { Immunodeficiency }\end{array}$ \\
\hline Musculoskeletal system & Dog & $\begin{array}{l}\text { Canine X-linked Muscular } \\
\text { Dystrophy }\end{array}$ \\
\hline Nervous system & Dog & Alzheimer's Disease \\
\hline Genes (genetic diseases) & Cat, dog & Mucopolysaccharidosis \\
\hline
\end{tabular}

\section{CONCLUSION}

It is important for pet owners to be aware of the many ways dogs and cats can help people with cancer. Being the owner of a dog or cat can improve the quality of your life, because you have fun with your pet, and you may be more physically active and feel less stressed. This is particularly true for people with cancer: when they spend time with their dogs or cats, they feel better. But in addition to the emotional benefits dogs and cats can provide for cancer patients, we now know that dogs and cats can also be of great help in finding the right strategies to cure them. Dogs and cats with cancer, together with veterinarians and veterinary scientists, can play a fundamental role in the long and difficult process of developing new, effective ways to treat or cure cancer.

\section{REFERENCES}

1. Regan, D., Garcia, K., and Thamm, D. 2018. Clinical, pathological, and ethical considerations for the conduct of clinical trials in dogs with naturally occurring cancer: a comparative approach to accelerate translational drug development. ILAR J. 59:99-110. doi: 10.1093/ilar/ily019

2. Lindblad-Toh, K., Wade, C. M., Mikkelsen, T. S., Karlsson, E. K., Jaffe, D. B., Kamal, M., et al. 2005. Genome sequence, comparative analysis and haplotype structure of the domestic dog. Nature. 438:803-19. doi: 10.1038/nature04338

3. Paoloni, M. C., and Khanna, C. 2007. Comparative oncology today. Vet. Clin. N. Am. Small Anim. Pract. 37:1023-32v. doi: 10.1016/j.cvsm.2007.08.003

4. LeBlanc, A. K., and Mazcko, C. N. 2020. Improving human cancer therapy through the evaluation of pet dogs. Nat. Rev. Cancer. 20:727-42. doi: $10.1038 / \mathrm{s} 41568-020-0297-3$

5. Cannon, C. M. 2015. Cats, cancer and comparative oncology. Vet. Sci. 2:111-26. doi: $10.3390 /$ vetsci2030111

SUBMITTED: 26 April 2021; ACCEPTED: 09 December 2021; PUBLISHED ONLINE: 04 January 2022. 
EDITED BY: Ajithkumar Vasanthakumar, Olivia Newton-John Cancer Research Institute, Australia

CITATION: Bongiovanni L, Bergman PJ and de Bruin A (2022) How Can Dogs and Cats Help to Cure Human Cancers? Front. Young Minds 9:700432. doi: 10.3389/ frym.2021.700432

CONFLICT OF INTEREST: The authors declare that the research was conducted in the absence of any commercial or financial relationships that could be construed as a potential conflict of interest.

COPYRIGHT (c) 2022 Bongiovanni, Bergman and de Bruin. This is an open-access article distributed under the terms of the Creative Commons Attribution License (CC BY). The use, distribution or reproduction in other forums is permitted, provided the original author(s) and the copyright owner(s) are credited and that the original publication in this journal is cited, in accordance with accepted academic practice. No use, distribution or reproduction is permitted which does not comply with these terms.

\section{YOUNG REVIEWER}

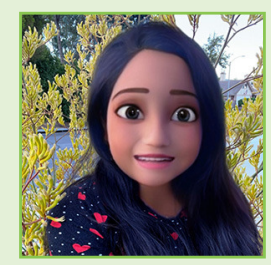

\section{ISABELLE, AGE: 11}

My name is Isabelle and I enjoy dancing, art, and making crafts. I enjoy learning about science because it is related to everyday life. Cooking has become my new hobby and I enjoy making my family meals. Spending time with my family is important to me and I try to do activities with them.
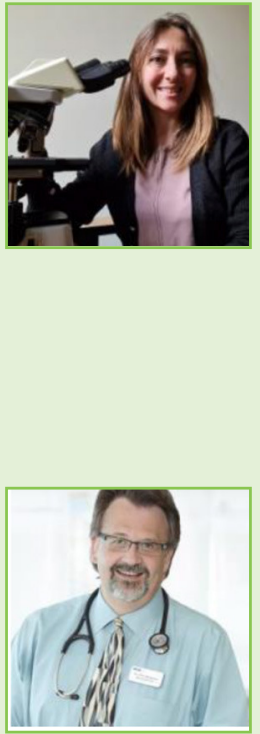

\section{AUTHORS}

\section{LAURA BONGIOVANNI}

Dr. Bongiovanni is a specialist in veterinary pathology and has dedicated her career to the study of canine cancers as a model of human cancer, for the development of novel tests and anti-cancer treatments. After graduating in 2003 from the University of Teramo, Italy, she obtained her Ph.D., degree working at the Utrecht University, Netherlands and at the University of Perugia, Italy. She is now working as an associate professor at the University of Teramo, Italy. She loves to spend time with her family (husband, two kids, and dog), talking about science and nature. *l.bongiovanni@uu.nl; lbongiovanni@unite.it

\section{PHILIP J. BERGMAN}

Dr. Bergman is specialist in veterinary oncology and he has dedicated his life to curing pets with cancer. After finishing veterinary school at Colorado State in 1990, he started working as oncologist. He completed a Ph.D., in human cancer biology from the M.D. Anderson Cancer Center in Houston in 1999. He was the head of the Donaldson-Atwood Cancer Center at AMC and chief medical officer for BrightHeart Veterinary Centers. He is now the director of clinical studies for VCA Animal Hospitals. He is the principal veterinary investigator for the fully licensed canine melanoma vaccine (Oncept). 


\section{ALAIN DE BRUIN}

Prof. de Bruin is a specialist in veterinary pathology. He has devoted his career to the study of cancer cell biology and animal models for human cancer. He obtained his D.V.M. degree in 1994 at the University of Hannover, Germany and performed his Ph.D., research in the field of cancer biology, graduating in 1999 from the University of Berne, Switzerland. His postdoctoral work was done at the Human Cancer Genetic Institute of the Ohio State University, USA. He is now a professor of pathobiology at Utrecht University, Netherlands. 